\title{
OBESITY AND EDUCATION IN THREE COUNTRIES OF THE CENTRAL AND EASTERN EUROPE: THE HAPIEE STUDY
}

\author{
Hynek Pikhart ${ }^{1}$, Martin Bobak ${ }^{1}$, Sofia Malyutina ${ }^{2}$, Andrzej Pajak ${ }^{3}$, Růžena Kubínová4, Michael Marmot ${ }^{1}$ \\ ${ }^{1}$ International Institute for Society and Health, Department of Epidemiology and Public Health, University College London, UK \\ ${ }^{2}$ Institute of Internal Medicine, Russian Academy of Medical Sciences, Novosibirsk, Russia \\ ${ }^{3}$ Department of Epidemiology and Population Studies, Jagiellonian University, Krakow, Poland \\ ${ }^{4}$ Centre for Environmental Health, National Institute of Public Health, Prague, Czech Republic
}

\section{SUMMARY}

The international pattern of obesity is only partly understood. While in developed countries the association between education and obesity is inverse, in the developing world social distribution of obesity is less predictable. We examined obesity patterns in three countries of Central and Eastern Europe (CEE): Russia, Poland and the Czech Republic, middle-income post-communist countries undergoing social and economic transition. The prevalence of obesity was inversely associated with education of individuals in our three samples of Central and Eastern European populations. In agreement with previous findings, the inverse socioeconomic gradient was more pronounced in the Czech Republic and Poland, countries with higher Gross National Product (GNP) than Russia. In addition, obesity was more common in Russian women than in Czech or Polish women while Russian men were less obese than Czech or Polish men. These findings are consistent with the hypothesis that the social gradient in obesity differs between populations - it is more likely to find a reverse association between socioeconomic position and prevalence of obesity in the more westernized countries with higher population income.

Key words: obesity, education, Central and Eastern Europe, social gradient

Address for correspondence: H. Pikhart, International Institute for Society and Health, Department of Epidemiology and Public Health, University College London, 1-19 Torrington Place, WC1E 6BT, UK. E-mail: h.pikhart@ucl.ac.uk

\section{INTRODUCTION}

Obesity is generally accepted as a risk factor for wide range of health outcomes, such as all cause mortality, cardiovascular mortality and morbidity or work disability (1). The international pattern is important for the epidemiology of obesity. Firstly, with respect to variation between countries, a recent report on 24 European countries has found that in both genders, obesity was more common in poorer countries of Europe; the highest prevalence of obesity was found in countries of Central and Eastern Europe (2). Ezzati et al. (3) has proposed inverse U-shape association between BMI and national income (with peak in BMI at about 12,500 USD in women and 17,000 USD in men). The countries of Central and Eastern Europe are among those with the highest BMI levels.

Second, within countries, obesity has been shown repeatedly to be inversely associated with socioeconomic status in developed countries (4) but the pattern seems to differ between high and low income countries. Monteiro et al. (5) reported that obesity among 20-49 years old women, belonging to the lower socioeconomic group, was of low prevalence in low-income countries but reached high rates in upper-middle income countries. Monteiro and colleagues suggested that obesity starts fuelling inequalities in health when gross national product (GNP) reaches approximately 2500 USD per capita.

In this paper, we examined obesity patterns in three countries of Central and Eastern Europe (CEE): Russia, Poland and the Czech Republic. Although the Czech Republic, Poland and Russia are all post-communist countries, there are relatively large differences in their economic development. GNP per capita in 2004 was 3,400 USD in Russia, 6,090 USD in Poland and 9,150 in the Czech Republic. The hypothesis by Monteiro et al. (5) predicts inverse association between BMI and GNP at these levels of GNP. Their model also predicts the largest inequalities in the Czech Republic and the smallest in Russia. We wanted to test whether Monteiro's inequality hypothesis could be used in these three CEE countries and to assess the levels of obesity in the region.

\section{MATERIAL AND METHODS}

\section{Data}

The data come from the baseline (wave 1) data of the Health, Alcohol and Psychosocial factors in Eastern Europe (HAPIEE) study, a study of urban samples in Russia, Poland and the Czech 
Republic (see 6 for detailed description of the study). The data for wave 1 of the study were collected in 2002-2005. In each country a sample of men and women 45-69 years old, stratified by gender and 5-year-age group was randomly chosen from population registers, and selected individuals were invited to participate in the study. The data analysed in this report were collected by a structured questionnaire and by the examination. Valid measurements of height, weight and valid data on age, sex and education were available for 25,482 men and women.

\section{Variables}

Measured height and weight were used in calculating bodymass index (BMI, $\mathrm{kg} / \mathrm{m}^{2}$ ) of individuals. Obesity was then defined as $\mathrm{BMI}>30 \mathrm{~kg} / \mathrm{m}^{2}$.

We used the highest level of completed education as the indicator of socioeconomic status. We categorised completed educational level into 4 categories: primary or less, vocational, secondary and university education.

\section{Statistical Analysis}

We calculated age-standardised rates of obesity for each country, gender and educational level. We used Stata (version 8) statistical package.

\section{RESULTS}

In our sample, the prevalence of obesity (body-mass index $>30$ $\mathrm{kg} / \mathrm{m}^{2}$ ) was extremely high (Table 1 ). It ranged from $21 \%$ (Russia) to 30\% (the Czech Republic) in men and from 32\% (the Czech Republic) to $47 \%$ (Russia) in women. More than $70 \%$ of study subjects were overweight (body-mass index $>25 \mathrm{~kg} / \mathrm{m}^{2}$ ).

Table 1 also displays prevalence of obesity by educational level. While there is strong inverse relationship between education and prevalence of obesity both in men and women in the Czech Republic, the association is much weaker (but highly significant, $\mathrm{p}<0.001$ ) in Polish men and there is non-significant association between obesity and education in Russian men. Among women, the association is strong and highly significant $(\mathrm{p}<0.001)$ in all 3 countries.

\section{DISCUSSION AND CONCLUSIONS}

We have shown that the prevalence of obesity is inversely associated with education of individuals in our 3 large middle-aged samples of Central and Eastern European populations. We have also shown that obesity is more common in women than in men in our populations. The gender difference increased with decreasing levels of GNP. This is consistent with paper by Rabin and colleagues (2) who showed that the gender differences in prevalence of obesity were the highest in poorer European countries, such as Romania and Russia.

In our data, educational gradient was more pronounced in women than in men in all 3 populations. This is consistent with previous findings of Molarius and colleagues (7) in 26 MONICA study populations. In all populations in their data analysis, women with higher education were leaner than women with lower education, and about half of men populations showed similar significant inverse association between education and BMI. In virtually all their populations, inverse educational gradient in BMI was clearer in women than in men.

Consistently with findings by Monteiro et al. (5), the inverse socioeconomic gradient was more pronounced in the Czech Republic and Poland, countries with higher GNP than Russia. These results support the hypothesis that the socioeconomic distribution of obesity differs by stage of country social and economic development.

Table 1. Body-mass index in men and women in the Czech Republic, Poland and Russia

\begin{tabular}{|l|l|c|c|c|}
\hline & & Czech Republic & Poland & Russia \\
\hline Men & & $\mathrm{N}=3223$ & $\mathrm{~N}=4451$ & $\mathrm{~N}=4201$ \\
\hline BMI mean & $\mathrm{kg} / \mathrm{m}^{2}$ & 28.4 & 28.0 & 26.6 \\
\hline \% with BMI $>25$ & all & $81 \%$ & $77 \%$ & $61 \%$ \\
\hline \% with BMI>30 & all & $30 \%$ & $27 \%$ & $21 \%$ \\
\hline & primary education & $45 \%$ & $31 \%$ & $22 \%$ \\
\hline & vocational education & $33 \%$ & $30 \%$ & $20 \%$ \\
\hline & secondary education & $27 \%$ & $27 \%$ & $21 \%$ \\
\hline Women & university education & $22 \%$ & $24 \%$ & $21 \%$ \\
\hline BMI mean & & $\mathrm{N}=3858$ & $\mathrm{~N}=4719$ & $\mathrm{~N}=5030$ \\
\hline \% with BMI>25 & kg/m & 28.3 & 30.2 \\
\hline \% with BMI>30 & all & $71 \%$ & $72 \%$ & $82 \%$ \\
\hline & all & $32 \%$ & $34 \%$ & $47 \%$ \\
\hline & primary education & $46 \%$ & $53 \%$ & $57 \%$ \\
\hline & vocational education & $36 \%$ & $41 \%$ & $48 \%$ \\
\hline & secondary education & $25 \%$ & $33 \%$ & $50 \%$ \\
\hline & university education & $19 \%$ & $24 \%$ & $38 \%$ \\
\hline
\end{tabular}




\section{What this Paper Adds}

- Obesity is major global problem. In Europe, obesity was more common in poorer countries; the highest prevalence of obesity was found in countries of Central and Eastern Europe.

- Within countries, obesity has been shown repeatedly to be inversely associated with socioeconomic status in developed countries. In the developing world, social distribution of obesity is less predictable.

- This study of Russian, Czech and Polish populations enables us to investigate the associations in post-communist countries undergoing social and economic transition.

- The inverse socioeconomic gradient in obesity was more pronounced in the Czech Republic and Poland, countries with higher GNP than Russia.

- Obesity was more common in Russian women than in Czech or Polish women while Russian men were less obese than Czech or Polish men.

\section{Policy Implications}

Social position influences the risk of obesity, and three countries described in this paper are among those European nations with increasing social inequalities. Any intervention that aims to target the high risk groups should consider social gradient, particularly as obesity levels are increasing rapidly. The observation of gender differences is important to plan gender specific public health interventions.

\section{Acknowledgments}

This study is funded by a grant from the Wellcome Trust "Determinants of Cardiovascular Diseases in Eastern Europe: A multi-centre cohort study" (Reference number 064947/Z/01/Z); a grant from the National
Institute on Aging "Health disparities and aging in societies in transition (the HAPIEE study)” (Grant number 1R01 AG23522-01); and a grant from MacArthur Foundation "Health and Social Upheaval (a research network)". MM holds a UK Medical Research Council Research Professorship. We would like to thank local collaborators and interviewers in Novosibirsk, Krakow, Havírov, Karviná, Jihlava, Ústí nad Labem, Liberec, Hradec Králové, Kroměříž.

\section{REFERENCES}

1. Visscher TL, Seidell JC. The public health impact of obesity. Annu Rev Public Health. 2001;22:355-75.

2. Rabin BA, Boehmer TK, Brownson RC. Cross-national comparison of environmental and policy correlates of obesity in Europe. Eur J Public Health. 2007 Feb;17(1):53-61.

3. Ezzati M, Vander Hoorn S, Lawes CM, Leach R, James WP, Lopez AD, et al. Rethinking the "diseases of affluence" paradigm: global patterns of nutritional risks in relation to economic development. PLoS Med. 2005 May;2(5):e133.

4. Sobal J, Stunkard AJ. Socioeconomic status and obesity: a review of the literature. Psychol Bull. 1989 Mar;105(2):260-75.

5. Monteiro CA, Conde WL, Lu B, Popkin BM. Obesity and inequities in health in the developing world. Int J Obes Relat Metab Disord. 2004 Sep;28(9):1181-6.

6. Peasey A, Bobak M, Kubínová R, Malyutina S, Pajak A, Tamosiunas A, et al. Determinants of cardiovascular disease and other non-communicable diseases in Central and Eastern Europe: rationale and design of the HAPIEE study. BMC Public Health. 2006 Oct 18;6:255.

7. Molarius A, Seidell JC, Sans S, Tuomilehto J, Kuulasmaa K. Educational level, relative body weight, and changes in their association over 10 years: an international perspective from the WHO MONICA Project. Am J Public Health. 2000 Aug;90(8):1260-8.

Received and accepted September 19, 2007 